\title{
Effect of Perioperative $\beta$-Blockers on Pulmonary Complications among Patients with Chronic Obstructive Pulmonary Disease Undergoing Lung Resection Surgery
}

\author{
A. Kamath, ${ }^{1,2}$ D. E. Stover, ${ }^{2}$ A. Hemdan, ${ }^{2}$ I. Belinskaya, ${ }^{2}$ R. M. Steingart, ${ }^{2}$ \\ Y. Taur, ${ }^{2}$ and M. B. Feinstein ${ }^{2}$ \\ ${ }^{1}$ Long Island Pulmonary and Sleep Associates, 200 North Village Avenues, Suite 300, Rockville Centre, NY 11750-5294, USA \\ ${ }^{2}$ Primary Research Institution, Memorial Sloan-Kettering Cancer Center, 1275 York Avenue, New York, NY 10021-9809, USA \\ Correspondence should be addressed to A. Kamath; avivakamath@gmail.com
}

Received 28 May 2015; Revised 13 August 2015; Accepted 19 August 2015

Academic Editor: Giovanni Luca Ceresoli

Copyright (C) 2015 A. Kamath et al. This is an open access article distributed under the Creative Commons Attribution License, which permits unrestricted use, distribution, and reproduction in any medium, provided the original work is properly cited.

The aim of this study is to determine if COPD patients undergoing lung resection with perioperative $\beta$-blocker use are more likely to suffer postoperative COPD exacerbations than those that did not receive perioperative $\beta$-blockers. Methods. A historical cohort study of COPD patients, undergoing lung resection surgery at Memorial Sloan-Kettering Cancer Center between 2002 and 2006. Primary outcomes were the rate of postoperative COPD exacerbations, defined as any initiation or increase of glucocorticoids for documented bronchospasm. Results. 520 patients with COPD were identified who underwent lung resection. Of these, 205 (39\%) received perioperative $\beta$-blockers and 315 (61\%) did not. COPD was mild among 361 patients (69\% of all patients), moderate in 117 patients (23\%), and severe in 42 patients (8\%). COPD exacerbations occurred among 11 (5.4\%) patients who received perioperative $\beta$-blockers and among 20 (6.3\%) patients who did not. Secondary outcomes, which included respiratory failure, 30-day mortality, and the presence or absence of any cardiovascular complication, ICU transfer, cardiovascular complication, or readmission within 30 days, did not differ in prevalence between the two groups. Conclusions. This study implies that perioperative $\beta$-blockers use among COPD patients undergoing lung resection surgery does not impact the rate of exacerbations.

\section{Introduction}

An estimated $71 \%$ of patients with non-small-cell lung cancer undergo potentially curative lung cancer resection in the United States every year [1]. Other than the lung, the heart is the organ most likely to suffer complications from lung resection [2]. Cardiac complications, which can include acute coronary syndrome, atrial fibrillation, and/or tachyarrhythmias, may prolong hospitalization and increase the overall financial cost of surgery [2-7]. The risk of cardiac complications can be decreased among some patients at high risk for acute coronary syndrome by the use of perioperative $\beta$-blockers. Mangano and colleagues, for instance, found that the use of atenolol, a $\beta_{1}$ selective agent, was associated with improved mortality among 200 V.A. patients with greater than two risk factors for coronary artery disease [8].

Unfortunately, $\beta$-blockers, especially those that bind nonselectively, have the potential to block the $\beta_{2}$ receptors of airway epithelium. Concern of precipitating bronchospasm in this fashion has led many investigators to exclude patients with chronic obstructive pulmonary disease (COPD) from clinical trials involving $\beta$-blockers. Such concerns may not be entirely justified [9]. Salpeter et al. demonstrated in a Cochrane review that 29 of 30 patients with asthma or COPD sufficiently severe to warrant chronic bronchodilators safely tolerated therapeutic levels of $\beta$-blockade with metoprolol or atenolol [10]. Au et al. demonstrated that $\beta$-blocker use among 1,966 patients with COPD and hypertension was associated with a lower all-cause mortality than use of other antihypertensives [11]. Finally, Çamsari et al. found that metoprolol given for coronary artery disease did not decrease the forced expiratory volume in one second (FEV1) among 50 patients with stable moderate to severe COPD [12].

Due to a common risk factor, smoking, many patients undergoing thoracic resection may suffer from heart disease 
and COPD concurrently [13-17]. As such, they represent a unique population who may benefit from the cardioprotective properties of $\beta$-blockers while concurrently being at increased risk for bronchospasm from the same medications. To our knowledge, all previously published studies of $\beta$ blocker use among COPD patients undergoing lung resection surgery have been case reports or lacked adequate controls. This study endeavored to include control patients to quantitate the potential risks and benefits of $\beta$-blocker use; its aim is to determine whether patients receiving perioperative $\beta$-blockers were more likely to suffer postoperative COPD exacerbations than those who did not.

\section{Methods}

We conducted a historical cohort study of COPD patients, undergoing lung resection surgery at Memorial SloanKettering Cancer Center between 2002 and 2006 (IRB approval number WA0264-04). Billing codes were used to identify patients who had undergone both pulmonary function tests and thoracic surgery at our institution. The PFTs for each individual patient were extractable electronically. All patients met the ATS criteria for COPD. COPD was defined as the ratio for forced expiratory volume in one second to forced vital capacity (FEV1/FVC) being less than or equal to $70 \%$ of predicted. Mild COPD was defined as having a percent predicted forced expiratory volume in one second (FEV1\%) greater than or equal to $80 \%$. Moderate COPD was defined as having a predicted FEV $1 \%$ between $50 \%$ and less than $80 \%$. Severe COPD was defined as having a predicted FEV1\% as less than $50 \%$ [18].

While the type and dose of $\beta$-blocker that each patient received was initially derived electronically from the medical record, a chart review was performed for each patient to confirm the dose and to delineate the patients who received $\beta$-blockers chronically from those who received only the perioperative dose. No dedicated pharmacy database was needed at our institution, as drug information is also available in detail using the general electronic medical record.

Patients who received $\beta$-blockers in response to postoperative cardiac events including tachyarrhythmia or acute coronary syndrome were excluded. Data derived from the medical record included patient age and sex; type of surgery (described as wedge resection, segmentectomy, lobectomy, or pneumonectomy); history of heart disease; spirometry, including measurement of the forced expiratory volume in one second, expressed as percent predicted (FEV1\%); diffusing capacity for carbon monoxide, expressed as percent predicted (DLCO\%); length of hospital stay in days; mortality at 30 days; the presence or absence of a postoperative ICU stay; and the presence or absence of any cardiovascular complications as defined in the following. Among patients who received $\beta$-blockers perioperatively, the specific drug, the dose, and the manner of delivery were also recorded.

The study was completed prior to the revised ACA/AHA 2014 guidelines; however, it would have been unusual to first start a $\beta$-blocker on the day of surgery. Perioperative $\beta$ blockade may have been started at the earliest three or so days before surgery based on individual prescribing practices.
Intravenous dosing of metoprolol $(5 \mathrm{mg}$ ) was noted to be given on an as needed basis in the pre- and intraoperative period, to keep the heart rate and blood pressure within parameters set by the ordering physician. Postoperatively, oral $\beta$-blockers are resumed with a divided dose equivalent of metoprolol 50-100 mg.

Included in primary outcomes is the presence or absence of a postoperative COPD exacerbation. An exacerbation was considered to have occurred if systemic glucocorticoids were prescribed for documented bronchospasm or if a preexisting systemic steroid dose was increased by the equivalent of $20 \mathrm{mg}$ of prednisone or more before hospital discharge. Patients receiving glucocorticoids for other causes were not considered to have suffered a COPD exacerbation. Secondary outcomes included the following: respiratory failure, 30-day mortality, and the presence or absence of any cardiovascular complication, ICU transfer, or readmission within 30 days. Respiratory failure was considered to have occurred when mechanical ventilation was necessary for more than 48 hours after thoracic surgery. A cardiovascular complication was defined as the development of acute coronary syndrome (ACS), congestive heart failure (CHF), and/or atrial fibrillation.

\section{Statistics}

Patients who had received perioperative $\beta$-blockers were compared to those who had not. Patients receiving $\beta$-blockers in response to an unexpected postoperative cardiac event, such as tachyarrhythmia or acute coronary syndrome, were not included in the $\beta$-blocker group. These predictors were first analyzed separately in a univariate model. To assess for confounding effects, variables with a univariate $p$ value of 0.25 or lower were included in a simultaneous multivariate model. Administration of perioperative antibiotics was included in the multivariate model regardless of univariate significance. A similar strategy was employed for secondary outcomes.

\section{Results}

Between 2002 and 2006, 520 patients who met the ATS criteria for COPD and underwent lung resection surgery at our institution were identified. Of these, 205 (69.8\%) patients received perioperative $\beta$-blockers and 315 (35.9\%) did not. Demographic information is summarized on Table 1.

Among all patients, COPD was mild among 361 (69\%), moderate in $117(23 \%)$, and severe among $42(8 \%)$. Patients prescribed $\beta$-blockers were slightly older (70 years old versus 67 years old (38\% versus 9\%; $p<0.0001)$ ). The extent of surgical resection, as well as the median FEV1\% and DLCO\%, was not different between the two groups. Among those prescribed $\beta$-blockers, 111 (54\%) patients had been receiving $\beta$-blocker medications chronically and 94 (46\%) received them only for the perioperative period. The incidence of cardiac complications which included acute coronary syndrome, atrial fibrillation, CHF, and others not specified was not statistically significant between the two groups. The composite cardiac endpoints were $34(16.6 \%)$ in the those patients 
TABLE 1: Clinical characteristics of patients that received perioperative $\beta$-blockers in comparison to those that did not. Data are expressed as the number of patients in each group.

\begin{tabular}{|c|c|c|c|}
\hline Clinical variable (\%) & $\beta$-blockers $(N=205)$ & No $\beta$-blockers $(N=315)$ & $p$ value \\
\hline Age $>60$ years & $175(85.4 \%)$ & $222(70.5 \%)$ & 0.0001 \\
\hline Male sex & $112(54.6 \%)$ & $130(41.3 \%)$ & 0.003 \\
\hline FEV $1 \%<50$ & $16(7.8 \%)$ & $26(8.3 \%)$ & n.s. \\
\hline DLCO $\%<50$ & $18(8.9 \%)$ & $32(10.3 \%)$ & n.s. \\
\hline \multicolumn{4}{|l|}{ Prior history } \\
\hline Asthma & $6(2.9 \%)$ & $15(4.8 \%)$ & n.s. \\
\hline Cardiac disease & $143(69.8 \%)$ & $113(35.9 \%)$ & $<0.0001$ \\
\hline Chronic renal insufficiency & $5(2.5 \%)$ & $4(1.3 \%)$ & n.s. \\
\hline Diabetes mellitus & $27(13.2 \%)$ & $25(7.9 \%)$ & n.s. \\
\hline Smoking within 6 months & $71(34.8 \%)$ & $127(40.3 \%)$ & n.s. \\
\hline \multicolumn{4}{|l|}{ Extent of lung resection } \\
\hline Sublobar & $48(23.4 \%)$ & $82(26.0 \%)$ & n.s. \\
\hline Lobectomy & $133(64.9 \%)$ & $200(63.5 \%)$ & n.s. \\
\hline Bilobectomy/pneumonectomy & $24(11.7 \%)$ & $33(10.5 \%)$ & n.s. \\
\hline \multicolumn{4}{|l|}{ Complications } \\
\hline COPD exacerbation & $11(5.4 \%)$ & $20(6.4 \%)$ & n.s. \\
\hline Respiratory failure & $7(3.4 \%)$ & $10(3.2 \%)$ & n.s. \\
\hline Cardiac complication & $18(8.8 \%)$ & $17(5.4 \%)$ & n.s. \\
\hline ICU transfer & $12(5.9 \%)$ & $15(4.8 \%)$ & n.s. \\
\hline Death $(30 \mathrm{~d})$ & $4(2.0 \%)$ & $1(0.3 \%)$ & n.s. \\
\hline
\end{tabular}

TABLE 2: Incidence of patients that developed cardiac complications. Data are expressed as the number of patients in each group.

\begin{tabular}{lccc}
\hline Cardiovascular complications & $\beta$-blockers $(N=205)$ & No $\beta$-blockers $(N=315)$ & \\
\hline Acute coronary syndrome (\%) & $1(0.5 \%)$ & $0(0 \%)$ & n.s. \\
Atrial fibrillation (\%) & $29(14.1 \%)$ & $49(15.6 \%)$ & n.s. \\
CHF (\%) & $1(0.5 \%)$ & $0(0 \%)$ & n.s. \\
Other & $3(1.5 \%)$ & $3(0.9 \%)$ & n.s. \\
Composite cardiac endpoints & $34(16.6 \%)$ & $52(16.5 \%)$ & n.s. \\
\hline
\end{tabular}

TABLE 3: Specific $\beta$-blocker used among 205 patients.

\begin{tabular}{lcc}
\hline B-blockers & $\begin{array}{c}\text { Number of } \\
\text { patients }(\% \text { of } \\
\text { patients) }\end{array}$ \\
\hline Cardioselective & Atenolol & $11(5 \%)$ \\
Nonselective & Propranolol & $187(91 \%)$ \\
\hline & Carvedilol & $1(1 \%)$ \\
& Labetalol & $2(1 \%)$ \\
\hline
\end{tabular}

receiving perioperative $\beta$-blockers versus $52(16.5 \%)$ in those patient that did not, as shown in Table 2. $\beta_{1}$ selective agents, such as metoprolol and atenolol, were prescribed much more commonly than nonselective agents, such as propranolol, labetalol, and carvedilol, as shown in Table 3. The use of noncardioselective $\beta$-blockers is suboptimal. However, this occurred at the discretion of the prescribing practice of individual physicians and not as a result of hospital protocol.
Overall, 5 patients (1\%) died within 30 days of surgery. Although more of these patients were in the group receiving $\beta$-blockers, the small number of events precluded any meaningful statistical analysis.

The primary outcome, COPD exacerbation, occurred following less than $10 \%$ of surgical procedures. The rate of COPD exacerbations did not differ between patients receiving and not receiving perioperative $\beta$-blockers $(p=$ 0.60 ). The secondary outcomes of respiratory failure, 30 -day mortality, and the presence or absence of any cardiovascular complication, ICU transfer, or readmission within 30 days each occurred among less than $10 \%$ of surgical procedures. No significant differences in the rates of these complications were noted between patients who received $\beta$-blockers and those who did not (data not shown). Clinical predictors of COPD exacerbation were assessed using univariate and multivariate logistic regression, as shown in Table 4.

Variables were identified prospectively and included age $>60$ years, male sex, whether or not perioperative $\beta$-blocker were given, FEV1\% <50, DLCO $\%<50$, asthma history, cardiac disease history, chronic renal insufficiency (CRI), diabetes mellitus, smoking within 6 months, and the extent of 
TABLE 4: Clinical predictors of COPD exacerbations.

\begin{tabular}{|c|c|c|c|c|}
\hline Variable & $\begin{array}{l}\text { Univariate } \\
\text { odds ratio }\end{array}$ & $\begin{array}{c}\text { Univariate } \\
p \text { value }\end{array}$ & $\begin{array}{c}\text { Multivariate } \\
\text { odds ratio }\end{array}$ & $\begin{array}{c}\text { Multivariate } \\
p \text { value }\end{array}$ \\
\hline Age $>60$ years & $3.06(1.06-12.95)$ & 0.04 & $2.50(0.84-10.72)$ & 0.11 \\
\hline Male sex & $1.42(0.69-2.99)$ & 0.34 & & \\
\hline Perioperative $\beta$-blocker given & $0.84(0.38-1.77)$ & 0.65 & & \\
\hline FEV $1 \%<50$ & $4.62(1.83-10.77)$ & 0.00 & $2.64(0.87-7.38)$ & 0.08 \\
\hline DLCO $\%<50$ & $4.39(1.82-9.90)$ & 0.00 & $2.83(0.98-7.57)$ & 0.05 \\
\hline Asthma & $1.79(0.28-6.63)$ & 0.48 & & \\
\hline Cardiac disease history & $1.71(0.82-3.68)$ & 0.15 & $1.69(0.79-3.76)$ & 0.18 \\
\hline Chronic renal insufficiency & $1.99(0.11-11.36)$ & 0.56 & & \\
\hline Diabetes mellitus & $0.96(0.22-2.83)$ & 0.94 & & \\
\hline Smoking within six months & $1.18(0.55-2.45)$ & 0.66 & & \\
\hline \multicolumn{5}{|l|}{ Extent of lung resection } \\
\hline Sublobectomy (referent) & $1.00(-)$ & - & & \\
\hline Lobectomy & $0.97(0.43-2.40)$ & 0.95 & & \\
\hline Bilobectomy/pneumonectomy & $0.84(0.18-3.03)$ & 0.80 & & \\
\hline
\end{tabular}

lung tissue resected (sublobectomy, lobectomy, or bilobectomy and pneumonectomy). On univariate analysis, clinical predictors associated with COPD exacerbation following lung resection as noted on Table 4 included the following: FEV $1<50 \%$, DLCO $<50 \%$, and smoking within six months. In multivariate analysis, only DLCO\% remained as an independent predictor. Use of perioperative $\beta$-blockers was not associated with COPD exacerbation in either univariate or multivariate analysis.

\section{Discussion}

Results of this study imply that perioperative $\beta$-blockade is generally safe at lung resection surgery. The Dutch Echocardiographic Cardiac Risk Evaluation Applying Stress EKG (DECREASE) trial, reporting a 90\% relative risk reduction in the combined endpoint of postoperative cardiac death and nonfatal myocardial infarction, included fabricated data and should, therefore, be discredited [19-22]. This was further challenged by the Perioperative Ischemic Evaluation (POISE) trial, a far superior randomized control trial, which showed an increased mortality and stroke with high dose perioperative $\beta$-blockade [23]. A more recent scientific review of the data by the American College of Cardiology and the American Heart Association in 2014 revised the clinical practice perioperative guidelines and should be taken into consideration when contemplating the use of perioperative beta-blockers. A class I B recommendation was given for the continuation of chronic $\beta$-blocker use perioperatively, a class II B recommendation was given for consideration of use in intermediate to high risk cardiac patients, and a class III $B$ recommendation states that beta-blockers should not be started on the day of surgery [24]. This study found that acute coronary syndrome occurred in $1(0.5 \%)$ of patients who received $\beta$-blockers in comparison to $0(0 \%)$ in patients who did not, the results of which are not statistically significant. Predictors of COPD exacerbation among patients receiving $\beta$-blockers included age greater than 60 years, FEV1 $<50 \%$, DLCO $<50 \%$, and any history of heart disease.

This study found that COPD exacerbations developed in about $6 \%$ of the patients, which is lower than that found by some other investigators. While Leo et al. noted a $12 \%$ rate [25], any perceived difference may result from differences in how COPD exacerbation was defined. Leo defined it by the absence of other pulmonary complications and the concomitant presence of three of the following five signs: worsening dyspnea, purulent sputum, bronchial secretion volume $>10 \mathrm{~mL} / 24 \mathrm{~h}$, fever without apparent cause, and wheezing. The definition of COPD exacerbation used in this study mandated the use of glucocorticoids for documented bronchospasm, which, while being more intuitive, may have missed milder exacerbations that did not require systemic steroids, resulting in a lower perceived rate. However, it is important to note that the severity of COPD in our study was no different between the two cohorts and that other studies resembling ours have reported similar rates of COPD exacerbation.

Anecdotal data suggest that many COPD patients who might otherwise qualify to receive $\beta$-blockers are not receiving them [9]. Data supporting the safety of perioperative $\beta$-blockers among COPD patients have significant clinical ramifications and imply a larger cohort of patients who might benefit from the cardio protective effects of these drugs. Results of this study add to the growing literature suggesting that $\beta$-blockers can be safely administered to COPD patients in specific clinical situations. van der Woude et al. showed that the use of Celiprolol, a $\beta_{1}$ selective blocker, did not cause any changes in lung function or bronchoreactivity [26]. In another study COPD patients undergoing major vascular surgery and receiving $\beta$-blockers had a lower 30 day and long-term mortality than those who did not [27]. A retrospective analysis by Dransfield et al. suggested that $\beta$ blocker use among patients hospitalized with acute COPD 
exacerbations was associated with decreased in-hospital mortality [28].

Postoperative atrial fibrillation developed in approximately $15 \%$ of the patients in this study. The rate of atrial fibrillation between the $\beta$-blocker and no $\beta$-blocker groups was similar despite the fact that the former group has a higher prevalence of heart disease (38\% versus $9 \%$ ). This rate is also similar to the incidence reported after lung resection in the nontreatment group of the retrospective study done by Okita et al. [19-22].

It is worthwhile noting some other limitations to this study. It is observational by design, and patients were limited to a single metropolitan cancer center in the Northeastern United States. The fact that more patients receiving $\beta$ blockers had previously documented heart disease suggests possible confounding by indication. It is expected, however, that this would have biased the results towards more frequent cardiac and pulmonary complications in the $\beta$-blocker group but it did not. The dose of $\beta$-blockers used in our cohort was generally small, which may have influenced the rate of respiratory complications. Similarly, most patients with COPD had relatively mild airways obstruction. Finally, it is possible that the sample size was insufficient to detect true differences in the rate of COPD exacerbations.

In summary, this study suggests that perioperative $\beta$ blocker use among COPD patients undergoing lung resection surgery is not associated with deleterious pulmonary complications or length of hospital stay, ICU admission, or 30-day mortality. Randomized interventional trials involving COPD patients are needed to confirm these findings.

\section{Abbreviations (in Alphabetical Order)}

ACS: $\quad$ Acute coronary syndrome

CHF: Congestive heart failure

COPD: Chronic obstructive pulmonary disease

DLCO\%: Diffusing capacity for carbon monoxide, expressed as percent predicted

FEV1: $\quad$ Forced expiratory volume in one second

FEV1/FVC: Forced expiratory volume in one second and forced vital capacity

FVC: $\quad$ Forced vital capacity.

\section{Conflict of Interests}

The authors declare that there is no conflict of interests regarding the publication of this paper.

\section{References}

[1] American Cancer Society, Cancer Facts \& Figures 2012, Secondary American Cancer Society, 2012, http://www.cancer.org/ research/cancerfactsfigures/cancerfactsfigures/cancer-facts-figures-2012.

[2] L. A. Fleisher, J. A. Beckman, K. A. Brown et al., "ACC/AHA 2007 guidelines on perioperative cardiovascular evaluation and care for noncardiac surgery: a report of the American College of Cardiology/American Heart Association Task Force on Practice Guidelines (Writing Committee to Revise the 2002 Guidelines on Perioperative Cardiovascular Evaluation for Noncardiac Surgery): developed in collaboration with the American Society of Echocardiography, American Society of Nuclear Cardiology, Heart Rhythm Society, Society of Cardiovascular Anesthesiologists, Society for Cardiovascular Angiography and Interventions, Society for Vascular Medicine and Biology, and Society for Vascular Surgery," Circulation, vol. 116, no. 17, 2007.

[3] A. D. Auerbach and L. Goldman, " $\beta$-blockers and reduction of cardiac events in noncardiac surgery: scientific review," The Journal of the American Medical Association, vol. 287, no. 11, pp. 1435-1444, 2002.

[4] A. S. Blaustein, "Preoperative and perioperative management of cardiac patients undergoing noncardiac surgery," Cardiology Clinics, vol. 13, no. 2, pp. 149-161, 1995.

[5] P. J. Devereaux, W. S. Beattie, P. T.-L. Choi et al., "How strong is the evidence for the use of perioperative $\beta$ blockers in noncardiac surgery? Systematic review and meta-analysis of randomised controlled trials," British Medical Journal, vol. 331, no. 7512, pp. 313-316, 2005.

[6] H. Yang, K. Raymer, R. Butler, J. Parlow, and R. Roberts, “The effects of perioperative $\beta$-blockade: results of the metoprolol after vascular surgery (MaVS) study, a randomized controlled trial," American Heart Journal, vol. 152, no. 5, pp. 983-990, 2006.

[7] P. K. Lindenauer, P. Pekow, K. Wang, D. K. Mamidi, B. Gutierrez, and E. M. Benjamin, "Perioperative beta-blocker therapy and mortality after major noncardiac surgery," The New England Journal of Medicine, vol. 353, no. 4, pp. 349-361, 2005.

[8] D. T. Mangano, E. L. Layug, A. Wallace, and I. Tateo, "Effect of atenolol on mortality and cardiovascular morbidity after noncardiac surgery," The New England Journal of Medicine, vol. 335, no. 23, pp. 1713-1720, 1996.

[9] M. R. Andrus, K. P. Holloway, and D. B. Clark, "Use of betablockers in patients with COPD," The Annals of Pharmacotherapy, vol. 38, no. 1, pp. 142-145, 2004.

[10] S. R. Salpeter, T. M. Ormiston, E. E. Salpeter, P. J. Poole, and C. J. Cates, "Cardioselective beta-blockers for chronic obstructive pulmonary disease: a meta-analysis," Respiratory Medicine, vol. 97, no. 10, pp. 1094-1101, 2003.

[11] D. H. Au, C. L. Bryson, V. S. Fan et al., "Beta-blockers as singleagent therapy for hypertension and the risk of mortality among patients with chronic obstructive pulmonary disease," American Journal of Medicine, vol. 117, no. 12, pp. 925-931, 2004.

[12] A. Çamsari, S. Arikan, C. Avan et al., "Metoprolol, a beta-1 selective blocker, can be used safely in coronary artery disease patients with chronic obstructive pulmonary disease," Heart and Vessels, vol. 18, no. 4, pp. 188-192, 2003.

[13] P. Almagro, E. Calbo, A. Ochoa de Echagüen et al., "Mortality after hospitalization for COPD," Chest, vol. 121, no. 5, pp. 14411448, 2002.

[14] N. R. Anthonisen, M. A. Skeans, R. A. Wise, J. Manfreda, R. E. Kanner, and J. E. Connett, "The effects of a smoking cessation intervention on 14.5-year mortality: a randomized clinical trial," Annals of Internal Medicine, vol. 142, no. 4, pp. 233-239, 2005.

[15] L. H. Kuller, J. K. Ockene, M. Townsend, W. Browner, E. Meilahn, and D. N. Wentworth, "The epidemiology of pulmonary function and COPD mortality in the multiple risk factor intervention trial," American Review of Respiratory Disease, vol. 140, no. 3, part 2, pp. S76-S81, 1989.

[16] M. S. Tockman and G. W. Comstock, "Respiratory risk factors and mortality: longitudinal studies in Washington County, Maryland," American Review of Respiratory Disease, vol. 140, no. 3, part 2, pp. S56-S63, 1989. 
[17] S. Vilkman, T. Keistinen, T. Tuuponen, and S.-L. Kivelä, "Survival and cause of death among elderly chronic obstructive pulmonary disease patients after first admission to hospital," Respiration, vol. 64, no. 4, pp. 281-284, 1997.

[18] B. R. Celli, W. MacNee, and A. E. T. Force, "Standards for the diagnosis and treatment of patients with COPD: a summary of the ATS/ERS position paper," European Respiratory Journal, vol. 23, no. 6, pp. 932-946, 2004.

[19] T. Okita, M. Uji, T. Shinjo et al., "Use of landiolol hydrochloride for the prevention of atrial fibrillation after lung resection," Japanese Journal of Anesthesiology, vol. 57, no. 8, pp. 953-958, 2008.

[20] D. Poldermans, E. Boersma, J. J. Bax et al., "The effect of bisoprolol on perioperative mortality and myocardial infarction in high-risk patients undergoing vascular surgery," The New England Journal of Medicine, vol. 341, no. 24, pp. 1789-1794, 1999.

[21] Erasmus Medical Centre, Report on the 2012 Follow-Up Investigation of Possible Breaches of Academic Integrity, 2012, https://cardiobrief.files.wordpress.com/2012/10/integrity-report-2012-10english-translation.pdf.

[22] G. D. Cole and D. P. Francis, "Perioperative $\beta$ blockade: guidelines do not reflect the problems with the evidence from the DECREASE trials," The British Medical Journal, vol. 349, Article ID g5210, 2014.

[23] P. J. Devereaux, H. Yang, S. Yusuf et al., "Effects of extendedrelease metoprolol succinate in patients undergoing non-cardiac surgery (POISE trial): a randomised controlled trial," The Lancet, vol. 371, no. 9627, pp. 1839-1847, 2008.

[24] D. N. Wijeysundera, D. Duncan, C. Nkonde-Price et al., "Perioperative beta blockade in noncardiac surgery: a systematic review for the 2014 ACC/AHA guideline on perioperative cardiovascular evaluation and management of patients undergoing noncardiac surgery: a report of the American college of cardiology/American heart association task force on practice guidelines," Journal of the American College of Cardiology, vol. 64, no. 22, pp. 2406-2425, 2014.

[25] F. Leo, N. Venissac, D. Pop et al., "Postoperative exacerbation of chronic obstructive pulmonary disease. Does it exist?" European Journal of Cardio-Thoracic Surgery, vol. 33, no. 3, pp. 424429, 2008.

[26] H. J. van der Woude, J. Zaagsma, D. S. Postma, T. H. Winter, M. van Hulst, and R. Aalbers, "Detrimental effects of beta-blockers in COPD: a concern for nonselective $\beta$-blockers," Chest, vol. 127, no. 3, pp. 818-824, 2005.

[27] Y. R. B. M. van Gestel, S. E. Hoeks, D. D. Sin et al., "Impact of cardioselective beta-blockers on mortality in patients with chronic obstructive pulmonary disease and atherosclerosis," American Journal of Respiratory and Critical Care Medicine, vol. 178, no. 7, pp. 695-700, 2008.

[28] M. T. Dransfield, S. M. Rowe, J. E. Johnson, W. C. Bailey, and L. B. Gerald, "Use of beta blockers and the risk of death in hospitalised patients with acute exacerbations of COPD," Thorax, vol. 63, no. 4, pp. 301-305, 2008. 


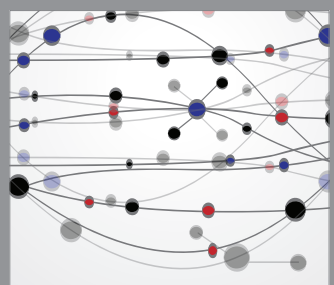

The Scientific World Journal
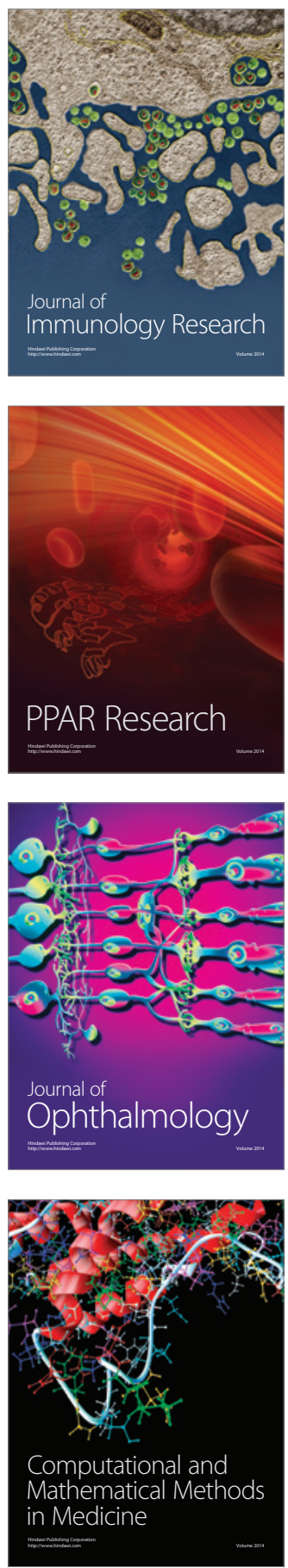

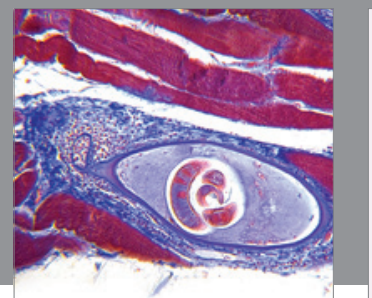

Gastroenterology

Research and Practice
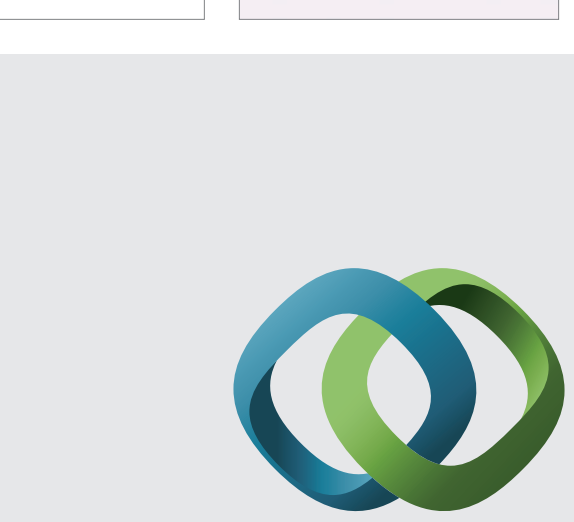

\section{Hindawi}

Submit your manuscripts at

http://www.hindawi.com
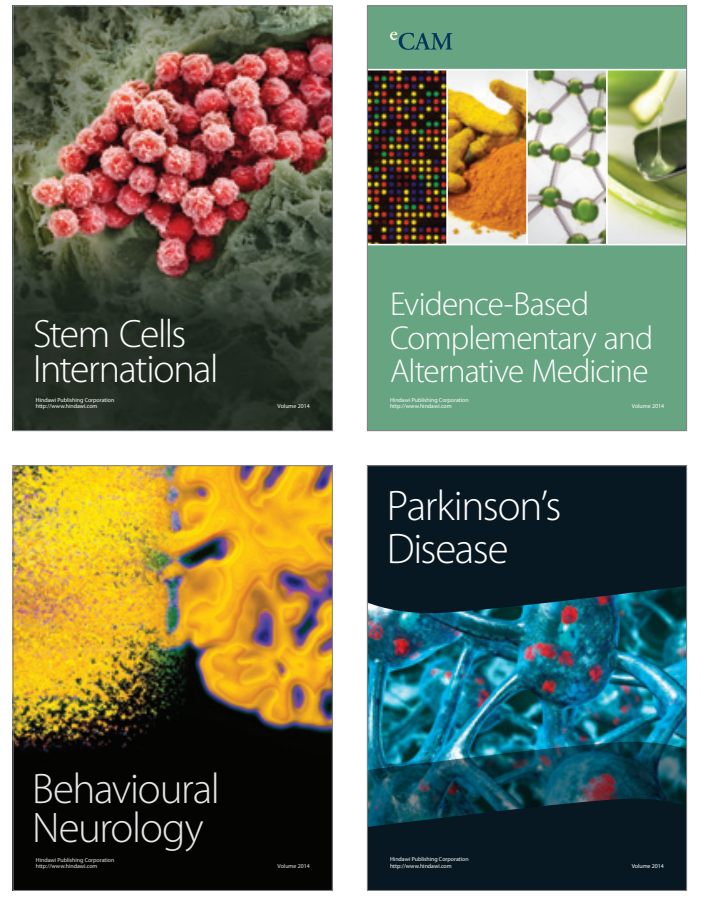
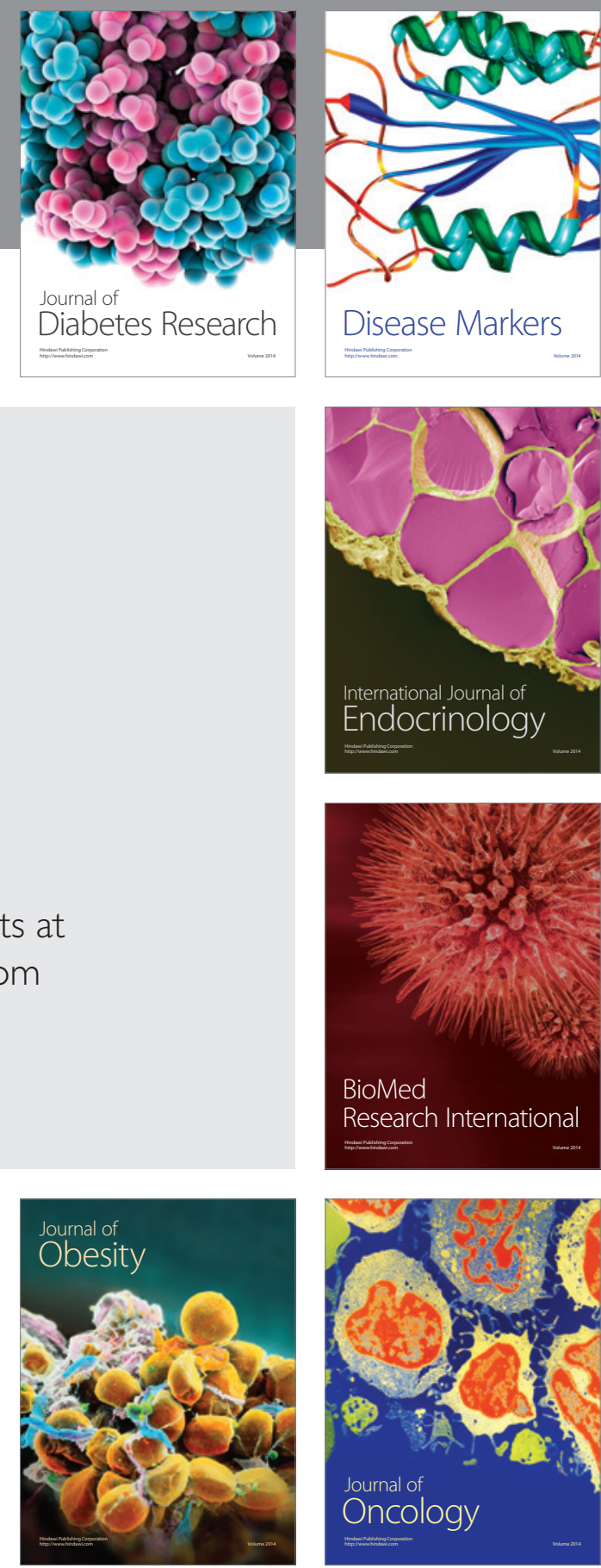

Disease Markers
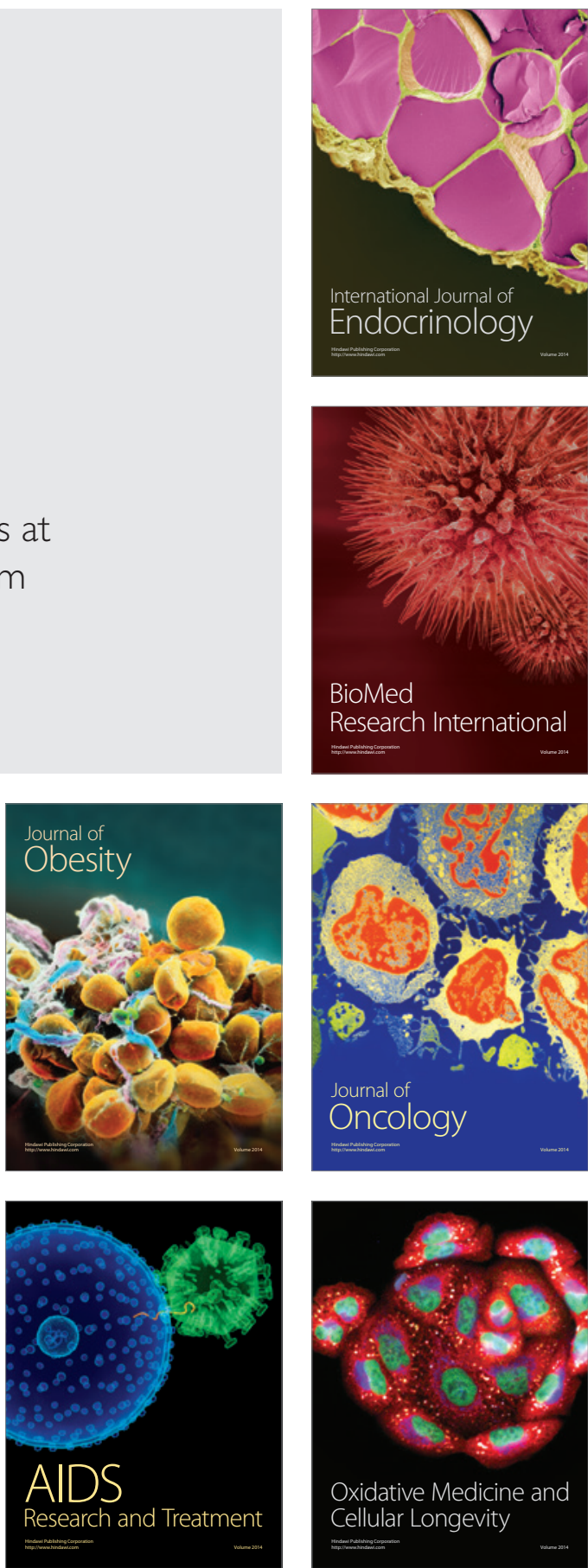